\title{
Effect of sintering temperature on structural and electrical properties of gadolinium doped ceria $\left(\mathrm{Ce}_{0.9} \mathrm{Gd}_{0.1} \mathrm{O}_{1 \cdot 95}\right)$
}

\author{
L D JADHAV*, S H PAWAR and M G CHOURASHIYA
}

Department of Physics, Shivaji University, Kolhapur 416 004, India

MS received 28 September 2006; revised 9 January 2007

\begin{abstract}
Gadolinium doped ceria oxide is one of the promising materials as an electrolyte for IT-SOFCs. $\mathrm{Ce}_{0.9} \mathrm{Gd}_{0.1} \mathrm{O}_{1.95}$ (GDC10) powder was prepared by solid state reaction and sintered at $1473 \mathrm{~K}, 1573 \mathrm{~K}, 1673 \mathrm{~K}$ and $1773 \mathrm{~K}$. All samples were studied using X-ray diffraction, scanning electron micrograph and d.c. conductivity measurement. The crystallinity and surface morphology of the samples improved with sintering temperature. Further, the electrical conductivity measurement indicated that the conduction mechanism is mainly ionic. The conductivity of samples sintered at $1673 \mathrm{~K}$ and $1773 \mathrm{~K}$ at $800^{\circ} \mathrm{C}$ are of the order of $0 \cdot 1 \mathrm{~S}-\mathrm{cm}^{-1}$. The activation energies decreased from $1 \cdot 25-0.82 \mathrm{eV}$ with increase in sintering temperature.
\end{abstract}

Keywords. $\quad \mathrm{Ce}_{0.9} \mathrm{Gd}_{0.1} \mathrm{O}_{1.95} ;$ IT-SOFC; XRD; SEM.

\section{Introduction}

Solid oxide fuel cells (SOFCs) are of two types based on their operating temperatures: high temperature SOFCs and low temperature or intermediate temperature SOFCs (i.e. IT-SOFCs). The problem encountered in commercializing HT-SOFC has motivated researchers to develop materials that could allow the SOFC operation at intermediate temperatures. Various groups around the world are involved in developing cathode, anode and electrolyte materials for IT-SOFC.

For IT-SOFC, the electrolyte material must have high ionic conductivity at comparatively lower temperature. The conventional YSZ $\left(\mathrm{Y}_{2} \mathrm{O}_{3}-\mathrm{ZrO}_{2}\right)$ electrolyte shows the required ionic conductivity (i.e. $0 \cdot 1 \mathrm{~S}-\mathrm{cm}^{-1}$ ) at $1000^{\circ} \mathrm{C}$; hence, it requires a higher operating temperature. In order to reduce the operating temperature, two approaches are widely applied. The resistance of dense electrolyte membranes is decreased by decreasing thickness of the traditional YSZ electrolyte or using alternative materials of higher ionic conductivity at comparatively lower temperatures (Mogensen et al 2000; Singhal 2000; Steele 2000a). Gadolinium-doped ceria (GDC) is one of the most promising electrolytes for SOFCs to be operated below $650^{\circ} \mathrm{C}$ (Sahibzada et al 2000; Steele 2000b; Zha et al 2001a, b). In view of the various advantages over the conventional electrolytes, YSZ and recently developed BICUMVOX material, we have planned to develop gadolinium doped ceria oxide as an electrolyte.

Various synthesis and processing methods have been used to prepare doped ceria with desired properties, in-

*Author for correspondence (lata_phy@unishivaji.ac.in) cluding hydrothermal synthesis (Hirano and Kato 1996), homogeneous precipitation (Herle et al 1996, 1997; Zha et al 2001c), sol-gel process (Huang et al 1997) and glycine-nitrate process (GNP) (Park et al 1997; Xia and Liu $2001 \mathrm{a}, \mathrm{b}$; Xia et al 2001). Further, solid-state reaction, a simple and cost-effective method, is often adopted to prepare bulk electrolyte samples (Wang et al 1998; Zhang et al 2003) and cathode materials (Gschneidner 1979; Qiu et al 2003).

In the present paper, we have prepared $\mathrm{Ce}_{0.9} \mathrm{Gd}_{0.1} \mathrm{O}_{1.95}$ (GDC10) by ceramic route. The material is then sintered at different temperatures and the effect of sintering temperature on the structural, morphological and electrical properties is discussed in detail.

\section{Experimental}

Commercially available powders of $\mathrm{CeO}_{2}(\mathrm{AR}, 99.9 \%$ HIMEDIA; make) and $\mathrm{Gd}_{2} \mathrm{O}_{3}$ (AR grade, $99.9 \%$ HIMEDIA, make) were used as starting materials. The powders of $\mathrm{CeO}_{2}$ and $\mathrm{Gd}_{2} \mathrm{O}_{3}$ were mixed in stoichiometric proportions to obtain GDC10 $\left(\mathrm{Ce}_{0.9} \mathrm{Gd}_{0.1} \mathrm{O}_{1.95}\right)$ compositions. The mixture was then homogenized by agate-mortar. The mixed powder was calcined at $1023 \mathrm{~K}$ for $2 \mathrm{~h}$ and reground with agatemortar. The powder was then hardened with hydraulic press machine at a pressure of about 10-12 tons/sq-inch in circular disk shaped pellets for all samples. The samples were then sintered at $1473 \mathrm{~K}, 1573 \mathrm{~K}, 1673 \mathrm{~K}$ and $1773 \mathrm{~K}$ for $2 \mathrm{~h}$ in air and identified as GDC114, GDC115, GDC116 and GDC117, respectively. The heating rate was kept at $3 \mathrm{~K} / \mathrm{min}$ and cooling rate was kept at $1 \mathrm{~K} / \mathrm{min}$ for all samples.

The phase composition of the sintered GDC10 pellets was studied using X-ray diffraction (PW-3710) with $\mathrm{Cu}-\mathrm{K}_{\alpha}$. 
The surface morphology of the samples was revealed using scanning electron microscope (SEM, JEOL-JSM-6360). The d.c. electrical conductivity of the samples was studied by two-probe method.

\section{Results and discussion}

\subsection{Structural characterization}

Figure 1 shows XRD patterns of the samples sintered at different temperatures, i.e. GDC114, GDC115, GDC116 and GDC117. The XRD data obtained for all four samples was compared with the JCPDS file no. 750161. All the samples showed the presence of (111), (200), (220), (311), (222), (400), (331), (420) and (422) reflection peaks in the scanning range $20-90^{\circ}$ of $2 \theta$. No impurity peaks were observed. This confirms the ' $f c c$ ' structure of prepared material.

The lattice parameter ' $a$ ' was calculated using the relation

$$
a=d \cdot \sqrt{h^{2}+k^{2}+l^{2}},
$$

and depicted in figure 2. The lattice parameter, $a$, for the GDC114 is $5.4045 \AA$, which increased to $5.4197 \AA$ for GDC115. Further increase in sintering temperature lowers the lattice parameter for both the GDC116 and GDC117

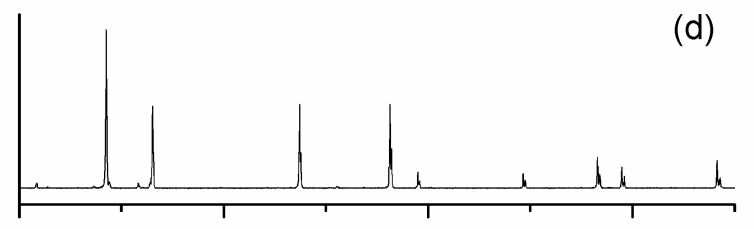

(c)
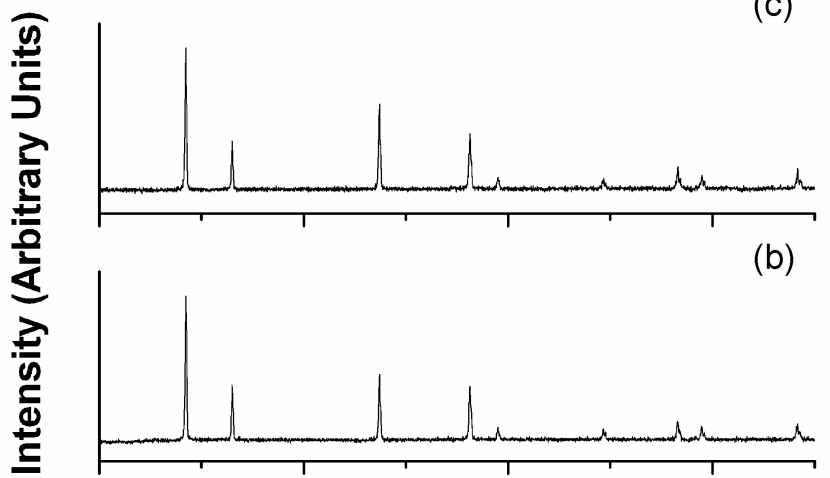

(b)
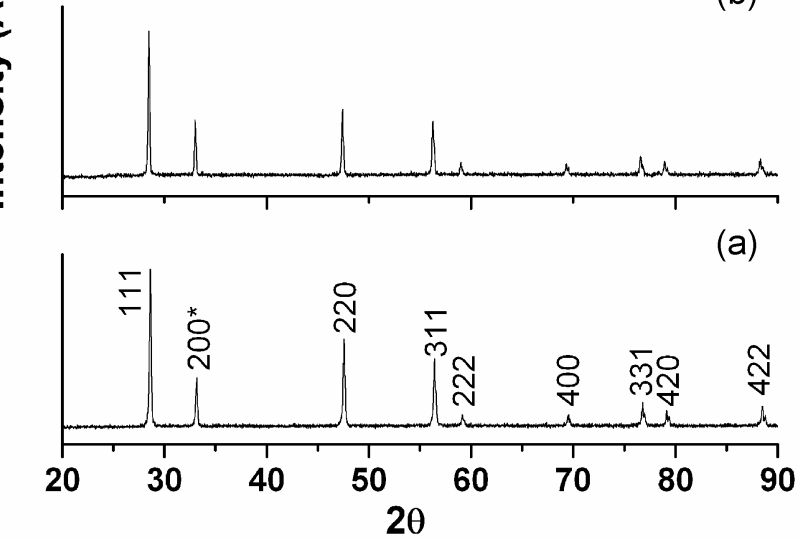

Figure 1. The XRD patterns of samples (a) GDC114, (b) GDC115, (c) GDC116 and (d) GDC117. samples. The lattice parameter for GDC116 and GDC117 is $5.4185 \AA$, which is in agreement with the reported value of 5.418 $\AA$ (Brauer and Gradinger 1954). It is also found that relative intensity of the diffraction peak (200) increases with sintering temperature, indicating a good crystal orientation (Song et al 2003).

The crystallite size of the samples sintered at different temperatures were calculated using the Scherrer's equation

$$
D=(0 \cdot 9 \lambda) /(\beta \cos \theta),
$$

where $\beta$ is the line broadening measured at half of height of peak, $\theta$ the angle of reflection and $\lambda$ the radiation wavelength.

The calculated crystallite size is presented in figure 3 . The size of crystallite is observed to improve with sintering temperature.

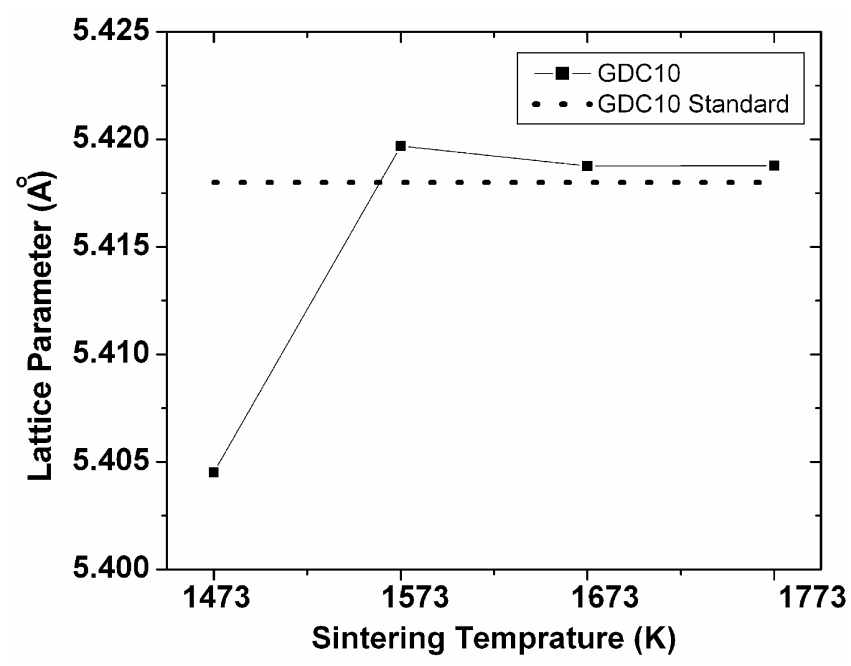

Figure 2. Variation in lattice parameter, $a$, of GDC10 sintered at different temperatures.

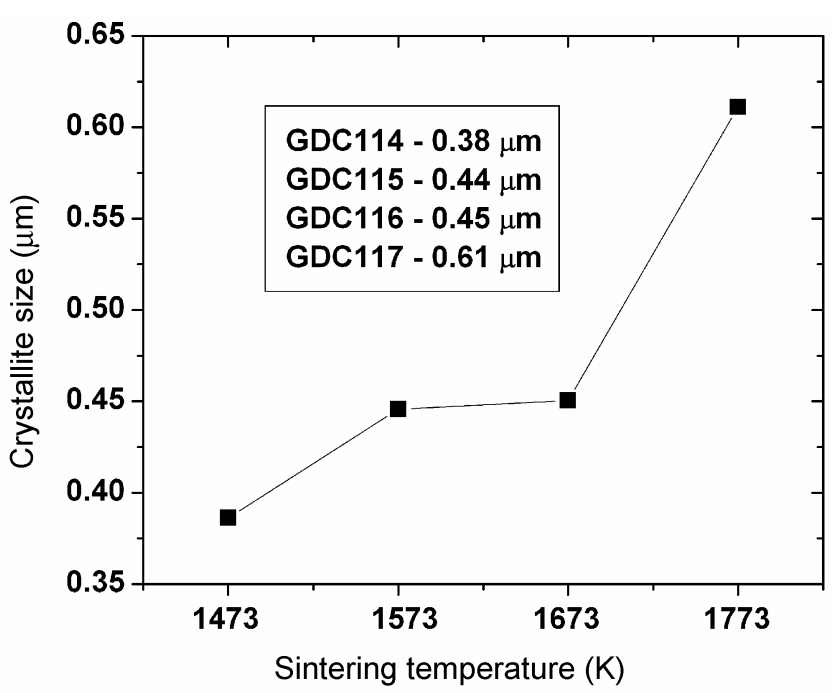

Figure 3. Variation in crystallite size for GDC10 samples as a function of sintering temperature. 

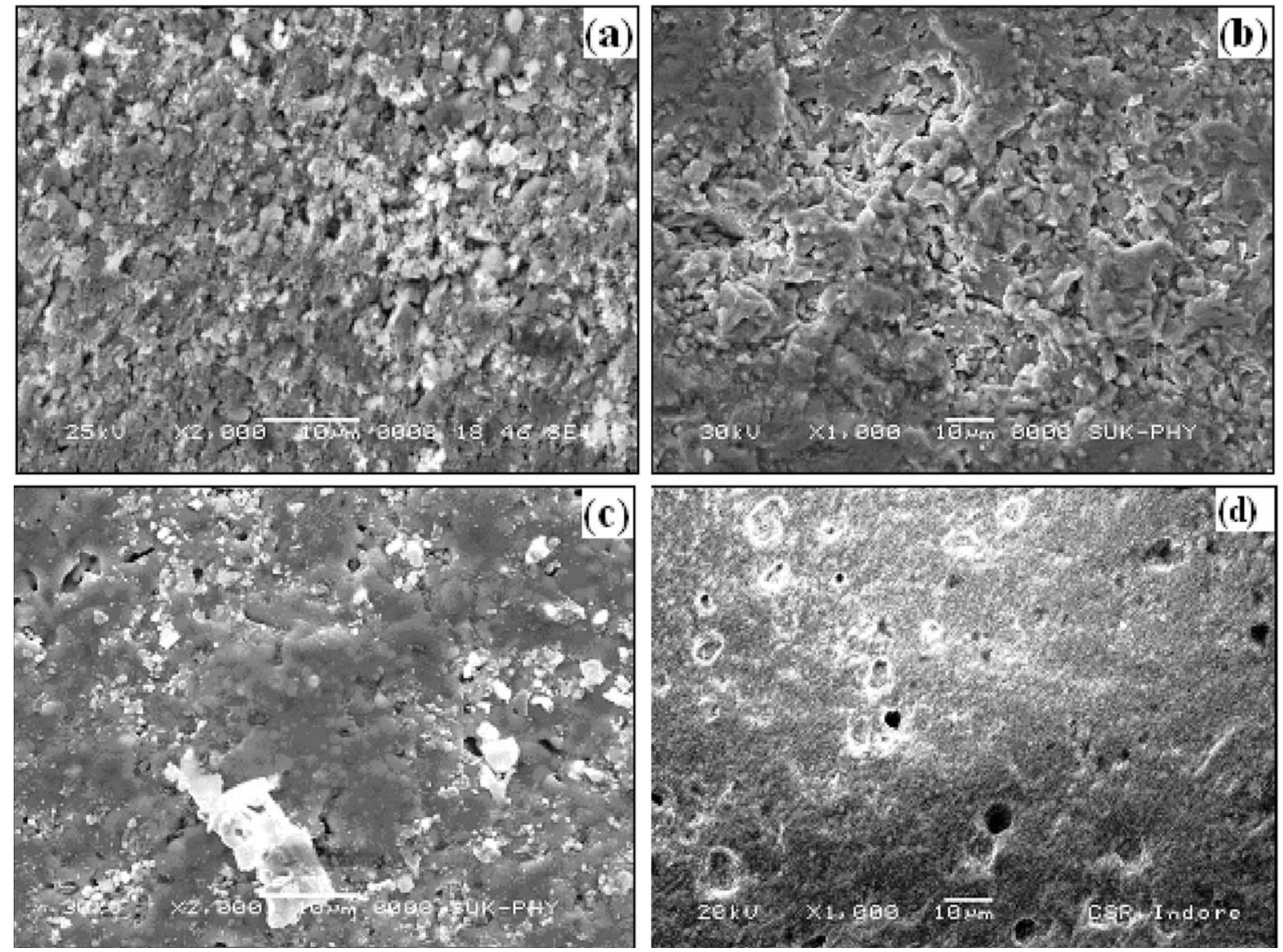

Figure 4. SEMs of samples: (a) GDC114, (b) GDC115, (c) GDC116 and (d) GDC117.

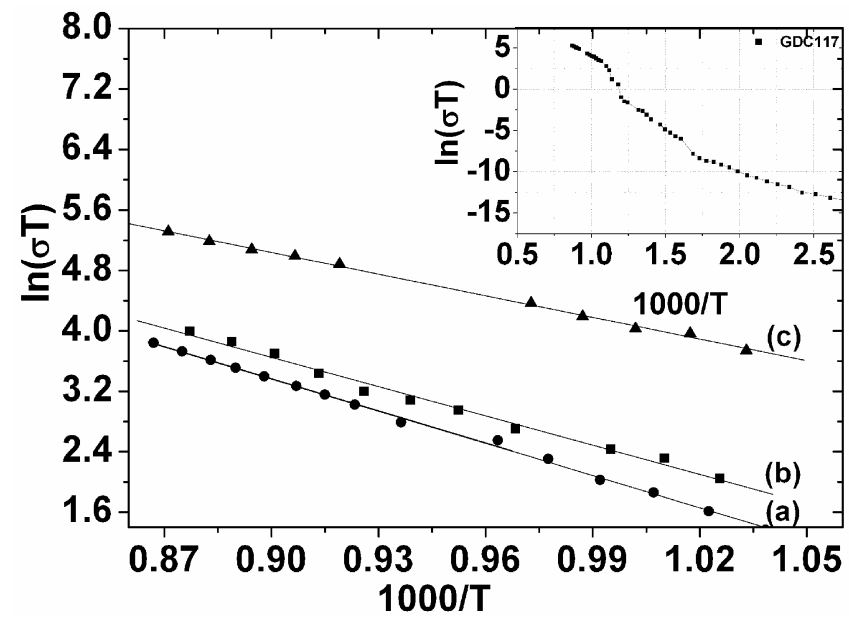

Figure 5. Variation of $\ln (\sigma T)$ with 1000/T: (a) GDC115, (b) GDC116 and (c) GDC117. Inset shows the variation of $\ln (\sigma T)$ with $1000 / \mathrm{T}$ of GDC117 in the temperature range $75-855^{\circ} \mathrm{C}$

\subsection{Morphological characterization}

Figure 4 shows SEM of samples GDC114, GDC115, GDC116 and GDC117. The SEM of all four samples clearly rectifies the effect of sintering temperature on its surface morphology. The amount of porosity as well as size of pores decreases as sintering temperature is increased. Also the surface gets modified and become smoother for higher sintering temperature. GDC117 is highly uniform and with no cracked surface.

The SEM at higher magnification gives direct estimation of grain size. The average grain size increased with sintering temperature and it being $0.75 \mu \mathrm{m}, 2 \mu \mathrm{m}, 2.5 \mu \mathrm{m}$ and $3 \mu \mathrm{m}$ for GDC114, GDC115, GDC116 and GDC117, respectively. This is consistent with XRD results.

\subsection{Conductivity measurement}

The d.c. conductivity measurement was done by two-probe method in air in the temperature range $298-1123 \mathrm{~K}$. The variation of $\ln (\sigma T)$ with $1000 / T$ for the GDC10 pellets sintered at $1473 \mathrm{~K}, 1573 \mathrm{~K}, 1673 \mathrm{~K}$ and $1773 \mathrm{~K}$ showed the change in slope at around $300^{\circ} \mathrm{C}$ and $650^{\circ} \mathrm{C}$ (inset of figure 5 for GDC117). The change in slope at $300^{\circ} \mathrm{C}$ is attributed to initiation of ionic diffusion and that at $650^{\circ} \mathrm{C}$ may be due to slight change in mechanism of conduction (Zha et al 2003). Figure 5 shows the $\ln (\sigma T)$ vs $1000 / T$ relation for GDC115, GDC116 and GDC117.

The conductivity at $800^{\circ} \mathrm{C}$ is tabulated in table 1 . The conductivity of GDC117 at $800^{\circ} \mathrm{C}$ is $0.121 \mathrm{~S}^{-\mathrm{cm}^{-1}}$, which almost equals the value of $\mathrm{YSZ}$ at $1000^{\circ} \mathrm{C}$ (Chen et al 
Table 1. The conductivities of samples GDC114, GDC115, GDC 116 and GDC 117 at $800^{\circ} \mathrm{C}$.

\begin{tabular}{lc}
\hline Sample & Conductivity at $800^{\circ} \mathrm{C}\left(\mathrm{S}-\mathrm{cm}^{-1}\right)$ \\
\hline GDC114 & $0.64 \times 10^{-3}$ \\
GDC115 & $0.94 \times 10^{-3}$ \\
GDC116 & $0.91 \times 10^{-3}$ \\
GDC117 & $0 \cdot 12$ \\
\hline
\end{tabular}

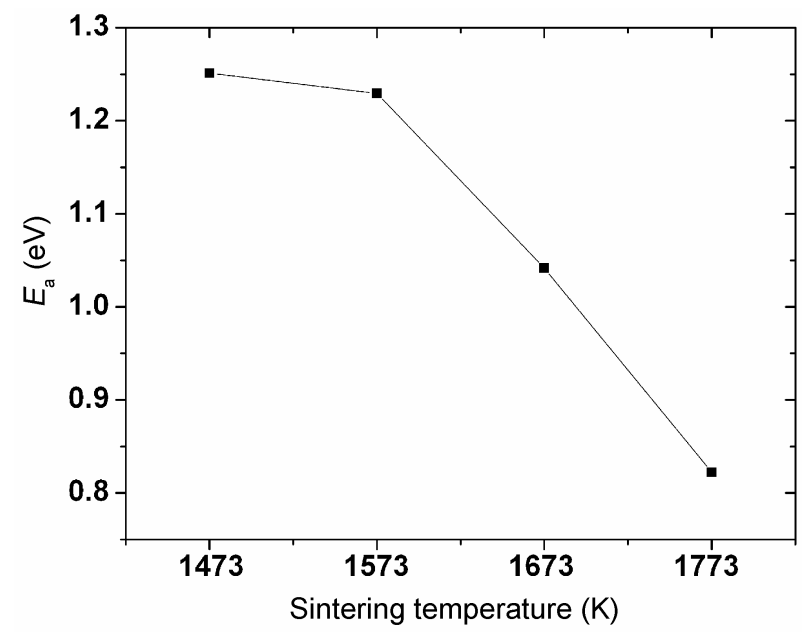

Figure 6. Variation of activation energy with sintering temperature.

2002) and slightly higher than the value of $0.118 \mathrm{~S}^{-\mathrm{cm}^{-1}}$ reported by Zha et al (2003).

Activation energies $\left(E_{\mathrm{a}}\right)$ for conductivity data were calculated by fitting the data to the Arrhenius relation for thermally activated conduction which is given as

$$
\sigma=\left(\sigma_{0} / T\right) \exp (E / K T)
$$

where $E_{\mathrm{a}}$ is the activation energy for conduction, $T$ the absolute temperature, $K$ the Boltzmann constant and $\sigma_{0}$ the pre-exponential factor. The linear fit is applied for the conductivity data using least square fitting technique.

Figure 6 shows the variation of activation energy with sintering temperature. The activation energy is decreased from $1 \cdot 251-0 \cdot 822 \mathrm{eV}$ with increase in sintering temperature.

Thus, sintering temperature affects conductivity and activation energy. With increase in sintering temperature conductivity increases and activation energy decreases. Since the doped cerias behave as pure ionic conductors in air with negligible electronic conductivity, the increased conductivity is attributed to the increase in grain interior conductivity (Xia and Liu 2002). We are now attempting to resolve this total conductivity into grain interior and grain boundary contributions.

\section{Conclusions}

The effect of sintering temperature on the structural, morphological and electrical properties of GDC10 was investigated. The samples sintered at and above $1673 \mathrm{~K}$, showed
' $f c c$ ' structure with lattice parameter, $a=5 \cdot 418 \AA$ Á. Further, the surface morphology of these samples showed decreased porosity and increased uniformity. The conductivity at $800^{\circ} \mathrm{C}$ is of the order of $\sim 0.12 \mathrm{~S} \mathrm{~cm}^{-1}$, which indicates that the developed material can be used as promising electrolyte for IT-SOFC.

\section{Acknowledgements}

The authors are very much thankful to DRDO for financial support. Also the authors are thankful to UGC-DAE Consortium for Scientific Research, Indore, for providing sintering facility.

\section{References}

Brauer G and Gradinger H 1954 Z. Anorg. Allg. Chem. 276209 Chen X J, Khor K A, Chan S H and Yu L G 2002 Mater. Sci. Eng, A335 246

Gschneidner K A Jr 1979 Handbook on the physics and chemistry of rare earths, non-metallic compounds (Amsterdam: NorthHolland Pub Co) Vol 3, p. 525

Herle J V, Horita T, Kawada T, Sakai N, Yokakawa H and Dokiya M 1996 Solid State Ionics 86-88 1255

Herle J V, Horita T, Kawada T, Sakai N, Yokakawa H and Dokiya M 1997 J. Am. Ceram. Soc. 80933

Hirano M and Kato E 1996 Commun. Am. Ceram. Soc. 79777

Huang W, Shuk P and Greenblatt M 1997 Solid State Ionics 10023

Mogensen M, Sammes N M and Tompett G A 2000 Solid State Ionics 12963

Park I S, Kim S J, Lee B H and Park S 1997 Jpn. J. Appl. Phys. 366424

Qiu L, Ichikawa T, Hirano A, Imanishi N and Takeda Y 2003 Solid State Ionics 15855

Sahibzada M, Steele B C H, Hellgardt K, Barth D, Effendi A, Mantzavinos D and Metcalfe I S 2000 Chem. Eng. Sci. 55 3077

Singhal S C 2000 Solid State Ionics 135305

Song H Z, Wang H B, Zha S W, Peng D K and Meng G Y 2003 Solid State Ionics 156249

Steele B C H 2000a Solid State Ionics 12995

Steele B C H 2000b Solid State Ionics 1343

Wang K, Ticky R S and Goodenough J B 1998 J. Am. Ceram. Soc. 812565

Xia C and Liu M 2002 Solid State Ionics 152423

Xia C R and Liu M L 2001a J. Am. Ceram. Soc. 841903

Xia C R and Liu M L 2001b For GNP, provisional patent application filed

Xia C R, Chen F L and Liu M L 2001 Electrochem. Solid-State Lett. 4 A52

Zha S, Fu Q, Lang Y, Xia C and Meng G 2001a Mater. Lett. 47351

Zha S, Xia C, Fang X, Wang H, Peng D and Meng G 2001b Ceram. Int. 27649

Zha S W, Fu Q X, Lang Y, Xia C R and Meng G Y 2001c Mater. Lett. 47351

Zha S, Xia C and Meng G 2003 J. Power Sources 11544

Zhang T S, Kong L B, Zeng Z Q, Huang H T, Hing P, Xia Z T and Kilner J A 2003 J. Solid State Electrochem. 7348 